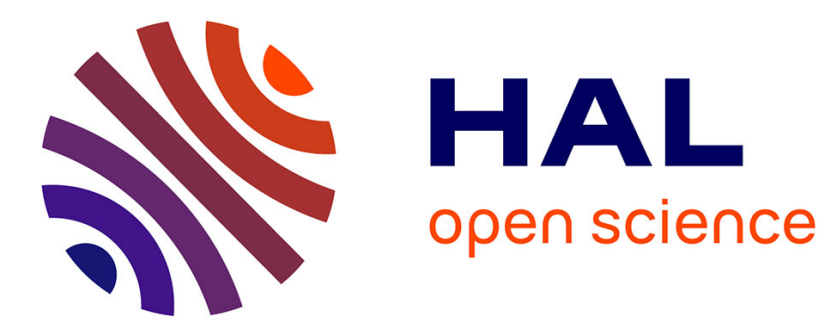

\title{
Transient variations of vertical total electron content over some African stations from 2002 to 2012
}

Amira Shimeis, Christine Amory-Mazaudier, Rolland Fleury, A.M. Mahrous, A.F. Hassan

\section{- To cite this version:}

Amira Shimeis, Christine Amory-Mazaudier, Rolland Fleury, A.M. Mahrous, A.F. Hassan. Transient variations of vertical total electron content over some African stations from 2002 to 2012 . Advances in Space Research, 2014, 54 (11), pp.2159-2171. 10.1016/j.asr.2014.07.038 . hal-01302424

\section{HAL Id: hal-01302424 \\ https://hal.sorbonne-universite.fr/hal-01302424}

Submitted on 14 Apr 2016

HAL is a multi-disciplinary open access archive for the deposit and dissemination of scientific research documents, whether they are published or not. The documents may come from teaching and research institutions in France or abroad, or from public or private research centers.
L'archive ouverte pluridisciplinaire HAL, est destinée au dépôt et à la diffusion de documents scientifiques de niveau recherche, publiés ou non, émanant des établissements d'enseignement et de recherche français ou étrangers, des laboratoires publics ou privés. 


\title{
Transient Variations of Vertical Total Electron Content
}

\author{
over Some African Stations from 2002 to 2012. \\ Advances in Space Research 54 (2014)
}

\section{9-2171}

\author{
A.Shimeis ${ }^{1,2}$, C. Amory-Mazaudier ${ }^{2,3}$, R.Fleury ${ }^{4}$,A.M. Mahrous ${ }^{1}$,A. F.Hassan ${ }^{1}$ \\ 1. Space Weather Monitoring Center (SWMC), Faculty of Science, Helwan University, Egypt \\ 2. LPP/Polytechnique/UPMC,CNRS ,4 Avenue de Neptune 94107 Saint-Maur des fossés, France \\ 3. ICTP, Trieste, Italy \\ 4. Lab-STICC UMR 6285 Mines-Télécom Télécom Bretagne, CS 83818, 29288 Brest, Cedex 3, \\ France \\ Corresponding author : Christine Amory-Mazaudier, tel : 33661851049, Fax : 33148894433, \\ e.mail : christine.amory@lpp.polytechnique.fr \\ Amira shimeis: email: amirashimeis@yahoo.com \\ Rolland Fleury : email : Rolland.Fleury@telecom-bretagne.eu \\ Ayman Mahrous: email : ayman.mahrous@gmail.com \\ Amin Hassan : email : aminhassan40@yahoo.com
}

\section{Abstract.}

This paper presents the vertical total electron content vTEC variations for three African stations, located at mid-low and equatorial latitudes, and operating since more than 10 years. The vTEC of the middle latitude GPS station in Alexandria, Egypt $\left(31.2167^{\circ} \mathrm{N} ; 29.9667^{\circ} \mathrm{E}\right.$, geographic) is compared to the vTEC of two others GPS stations: the first one in Rabat/Morocco $\left(33.9981^{\circ} \mathrm{N} ; 353.1457^{\circ} \mathrm{E}\right.$, geographic), and the second in Libreville/Gabon $\left(0.3539^{\circ} \mathrm{N} ; 9.6721^{\circ} \mathrm{E}\right.$, geographic). Our results discussed 
the diurnal, seasonal, and solar cycle dependences of vTEC at the local ionospheric conditions, during different phases of solar cycle in the light of the classification of Legrand and Simon. The vTEC over Alexandria exhibits the well-known equinoctial asymmetry which changes with the phases of the solar cycle; the spring vTEC is larger than that of autumn during the maximum, decreasing and minimum phases of solar cycle 23. During the increasing phase of solar cycle 24 , it is the contrary. The diurnal variation of the vTEC presents multiple maxima during the equinox from 2005 to 2008 and during the summer solstice from 2006 to 2012. A nighttime vTEC enhancement and winter anomaly are also observed. During the deep solar minimum (2006 -2009) the diurnal variation of the vTEC observed over Alexandria is similar to the diurnal variation observed during quiet magnetic period at equatorial latitudes. We observed also that the amplitude of vTEC at Libreville is larger than the amplitude of vTEC observed at Alexandria and Rabat, indeed Libreville is near the southern crest of the Equatorial Ionization Anomaly. Finally, the correlation coefficient between vTEC and the sunspot number Rz is high and changes with solar cycle phases.

Key words: Ionosphere, equinoctial asymmetry, solar cycle 


\section{Introduction}

At mid-low latitudes, the total electron content of the F2 region ionosphere does not always decrease throughout the night as is expected by the simple Chapman theory. But meridian neutral winds also play an important role in controlling the peak height and density of the F layer, and are largely responsible for maintaining the nighttime ionosphere at mid-latitudes (Rishbeth, 1972, 1974), as single or double peak formations in latitude under various geomagnetic conditions.

Nighttime enhancement in ionospheric total electron content (TEC) is a well-known equatorial, low and middle latitude phenomenon and has been studied by many authors ( Arendt and Soicher in 1964; Klobuchar et al., 1968; Davies et al., 1979;Leitinger et al., 1982; Balan and Rao, 1987; Balan etal., 1991; Bailey et al., 1991 ; Horvath and Essex, 2000), The enhancements are caused mainly by the downward flow of plasma from the protonosphere to the ionosphere for mid-latitudes (Arendt and Soicher, 1964; Evans, 1965c, 1965d; Da Rosa and Smith, 1967; Jain and Williams, 1984; Jakowski et al., 1991; Jakowski and Förster, 1995; Mikhailov et al., 2000)and the plasma transfer from the conjugate ionosphere (Bertin and 
Lepine, 1970; Bailey et al., 1992; Balan et al., 1991, 1994; Garner et al., 1994; Richards et al., 2000).

In the low latitude ionosphere, the nearly horizontal geomagnetic field lines combine with the neutral wind and electric field to create some unique phenomena called the equatorial anomaly. The morphology of the equatorial region is characterized by a trough at the magnetic equator and two crests of ionization at about $( \pm 17)$ magnetic latitudes that is controlled by the electric field, neutral winds and magnetic declination angle between the magnetic and geographic equators. Several important low latitude phenomena associated with the electrodynamics processes were investigated which include (1) the daytime equatorial electrojet (EEJ); (2) the daytime ionospheric vertical drifts; and (3) the post-sunset pre-reversal enhancement (PRE) of the vertical drifts.

An interesting feature of the vertical drift is the enhancement of upward drift at around 19:00 LT. This phenomenon is called the pre-reversal enhancement (PRE) which has a strong influence on the morphology of the nighttime low-latitude ionosphere. Some theories suggested that the enhanced electric field is closely associated with the action of an eastward thermospheric wind in ionosphere F-region and the longitude gradient on the 
integrated Pedersen conductivity that exists across the sunset (Rishbeth, 1971, 1972, 1974; Heelis et al., 1974; Farley et al., 1986; Crain et al., 1993). At solstice, for altitudes above the F-region peaks, the major difference between the two solstice conditions is the change in solar zenith angle and, consequently, EUV ion production when viewed in either the geographic or magnetic frame. This effect is further strengthened by the eccentric nature of the dipole axis, leading to significant hemispherical differences (Sojka and Schunk, 1985, 1989). The meridional neutral winds modulate the fountain differently at different altitudes and latitudes from the summer to the winter hemisphere. At equinox, the zonal neutral winds modulate the fountain to supply more ionization to the northern hemisphere during evening and nighttime hours (Balan N. et al., 1995)

Theoretical modeling studies have verified that an E x B drift is the major mechanism responsible for these peaks and have shown how the neutral wind and longitudinal effects cause asymmetries in the peaks (Hanson and Moffett, 1966; Sterling et al., 1969; Abur-Robb and Windle, 1969; Anderson, 1973a, b, 1981).

These phenomena can be fully explained by a combined theory of the transequatorial neutral wind, the subsolar point, and the auroral equatorward wind (Tsai et al, 2001). 
Study of ionospheric variations of the vertical vTEC at low-middle ionosphere shows dependence on solar activity. Long term studies in variations of critical frequency foF2 at low latitudes have been made in African zones by a number of workers (Olapido et al., 2008;Adohi et al., 2008,; Ouattara et al, 2009; Obrou et al., 2009 ; Thiam et al., 2012; Ouattara and Amory-Mazaudier, 2012; Ouattara et al., 2012).

There are a limited number of GPS receivers operating in this sector, since more than 10 years, only three. The three GPS receivers are located at Alexandria/Egypt, Rabat/Morocco, and Libreville/Gabon; see figure1. Table 1 gives the geographic and geomagnetic coordinates of the three GPS stations. The local times for each station are calculated $($ U.T. $+2 \mathrm{Hrs}=$ ALEX L.T.), (U.T. + OHr = RABT L.T.), and (U.T. + 1Hr = NKLG L.T.). Very few publications on longterm variations of the vTEC are available (Moekesti et al., 2007).

The purpose of the present work is to present for the first time in African sector, the diurnal, seasonal, and solar cycle dependences of vTEC on the local ionospheric conditions at the three GPS stations.

Our period of observations, 2002- 2012, includes one year of solar maximum of cycle 23, 2002, the decreasing phase of solar cycle 23, 2003- 
2005, the deep solar minimum, 2006-2009, and the increasing phase of solar cycle $24,2010-2012$.

Ouattara and Mazaudier (2012) showed that the different types of solar activity occurring during the different phases of solar cycle modified the diurnal pattern of ionization. They used the classification of Legrand and Simon made on one century (1868-1978) of geomagnetic activity, using the Mayaud's Aa index (Legrand and Simon, 1989). These classes related to solar activity are: (1) the magnetic quiet activity due to slow solar wind flowing around the magnetosphere, (2) the recurrent activity related to high wind speed solar wind, (3) the fluctuating activity related to fluctuating solar wind and (4) the shock activity due to shock events (CME). We will discuss our results at the light of this classification.

The second section of this paper presents the data set and data analysis and the third one the results and discussion. The last section is the conclusion

\section{Data Set and Data Analysis}

The GPS satellites that orbit the Earth, at altitude 20,200 km above the Earth's surface provide the Total Electron Content (TEC): total number of 
electrons integrated along the path from receiver to each GPS satellite. The TEC is expressed by

$$
T E C=\int_{R}^{S} N_{e}(h) d h
$$

Where $n_{e}$ is electron density, $R$ is the receiver altitude and $S$ the satellite altitude. TEC is measured in TEC Unit (TECU), $1 T E C U=10^{16}$ electron $/ \mathrm{m}^{2}$. GPS receivers provide both carrier phase delays $\mathrm{L}$ and pseudo ranges $\mathrm{P}$ of the dual frequencies. Each satellite of the GPS satellites constellation broadcasts two L-band signal at two frequencies. TEC obtained by using dual frequency (as GPS satellites broadcast two L-band signals at two frequencies) concerned the GPS stations of ALEX during the period from 2002 to 2012.

ALEX GPS station was installed in 2000 and the resultant data Leica GPS receiver channels L1 and channels L2 has been available for free downloading from the internet through the website (http://www.stationgps.cea.com.eg/siteGPS/).

There are two cases to calculate relative phase delay between the two carrier frequencies: 
1) The pseudo range method gives an absolute scale of TEC with less precision, and

2) The differential phase method, which increases measurement precision, but does not allow knowing the number of cycles of phase.

The absolute TEC is impossible to obtain (Klobuchar, 1996).

To obtain accurate TEC estimation, we follow Sardon et al. (1994) by removing differential instrument biases because satellites and receivers for the GPS observables are biased on the instrumental delays (Norsuzila et al., 2009).

The fundamental GPS frequency is $f_{0}=10.23 \mathrm{MHz}$ from which $f_{1}$ and $f_{2}$ are derived $\left(f_{1}=1575.42 \mathrm{MHz}=154 . f_{0}\right.$ and $\left.f_{2}=1227.60 \mathrm{MHz}=120 . f_{0}\right)$, defined the group delay as:

$$
P_{1}-P_{2}=40.3 T E C\left(\frac{1}{f_{1}^{2}}-\frac{1}{f_{2}^{2}}\right) V
$$

$P_{1}$ and $P_{2}$ are the pseudo ranges for $f_{1}$ and $f_{2}$ respectively. By rewriting the equation of group delay, we obtain:

$$
T E C=\frac{\left(P_{1}-P_{2}\right)}{40.3} \frac{f_{1}^{2} f_{2}^{2}}{f_{2}^{2}-f_{1}^{2}}
$$


The TEC between the satellite and the user depends on the satellite elevation angle; this measurement is called Slant TEC (sTEC). The TEC varies temporally and spatially, and it depends on the solar activity, user location, and the satellite elevation angle. This measurement is named vertical TEC (vTEC). To convert sTEC to vertical TEC (vTEC), it is customary to assume the Earth's ionosphere as a thin-shell model at a fixed height $\left(h_{s}\right)$ in the range 350-400 km (Klobuchar, 1996).

To convert sTEC to vTEC we used the following equation:

$$
V T E C=\left(s T E C-B_{s}-B_{u}\right)\left(\sqrt{1-\left(\frac{R_{e} \times \cos (\varepsilon)}{R_{e}+h_{s}}\right)^{2}}\right)
$$

$B_{s}$ and $B_{u}$ are the instrumental biases of satellites and receivers respectively; $R_{e}=6371 \mathrm{~km}$ is the mean radius of the Earth; "is the elevation angle of the satellite (Titheridge, 1972).

Such a 'shell model' has many advantages including mathematical simplicity and assumes that the ionosphere is compressed in the radial direction around the F2 layer of the ionosphere. So, this method gives errors when gradients of ionization exist in the horizontal plane (transition day/night, equatorial crests for example): typically some percent of TECU but up to10\% during big ionospheric storms. 
Several studies have been conducted to increase the accuracy of the result

- Characterize the vertical ionization in electron density by many empirical orthonormal functions deduced from IRI95 model (Smith et al., 2008)

- Use tomographic methods with also an initial profile to facilitate the convergence of the system (Meggs et al., 2006)

- In these two cases, the number of variables will be important and the solution is obtained from a network of stations with time integration of several minutes of data.

- Some improvements by a multi-layer model with different height for each thin-shell (Komjathy et al., 2002). The RMS residuals are reduced but give some instable solution in some cases.

We want to calculate vTEC only around the GPS receiver and not in a geographical area. Our approach is to not use the data under $25^{\circ}$ of elevation angle where the thin-shell approximation is less valid.

In this study, we analyze vTEC variations during solar cycle different phases along annual, seasonal and diurnal variation. The daily mean vTEC values are derived from the available GPS data. Seasonal variation is obtained by using mean values of monthly values. Annual variation is obtained by using monthly mean values at local noon. Our seasons are the following: winter 
(December, January, and February), summer (June, July, August), autumn (September, October, November), and spring (March, April, May) .The study is performed for the different phases of solar cycles. Table 1 gives the geographic and geometric locations. Table 2 gives the classification of selected years and sunspot numbers according to the solar cycle phases.

\subsection{Diurnal Variation}

To illustrate the results of our method, we plotted in Figure 2a the variations of vTEC according to UTC time. Each point in the figure represents a measure in RINEX files April 7, 2012 for the stations ALEX and NKLG. In these two cases, spread diurnal variation gives an order of magnitude of the error, which was observed: From peak to peak, the spread is 10 TECU and 15 TECU during the night of the ALEX and NKLG respectively ,at daytime the values are higher (15and 30 for ALEX and NKLG respectively, related to a stronger presence of gradients. The variation of the vertical TEC in the station is estimated by smoothing these measures, weighted by elevation angles of a sliding window analysis $15 \mathrm{~min}$. we deduce the continuous curve drawn in blue, that will much more regular and represent the diurnal variation. 
Figure 3 shows the diurnal (x-axis) variation of mean monthly vTEC measurements at ALEX station, during maximum and minimum of the solar cycle the solid lines represent the vTEC at the solar maximum (2002) and the dash lines for the vTEC at solar minimum ( 2007) of the solar cycle. Table 1 provides the geographic and geomagnetic coordinates of the ALEX station.

Geomagnetic seasons are classified summer (May, June, July, August), winter (November, December, January February) and equinox (March, April, September, October). As recent studies (Pham et al., 2011) showed a large asymmetry between the two equinoxes, this study has investigated the two equinoxes separately. This separation is also consistent with the seasons given by the zonal mean circulation of winds in the thermosphere (Roble et al., 1977). The winds are flowing from the summer to the winter during summer times and reverse during winter times.

At the maximum of solar cycle in 2002, the maximum value of vTEC is observed in February/March and the minimum in December/July. In March (vernal equinox) 2002, the vTEC variation curve has one ionization peak at 10:00 U.T. which is the local noon at ALEX (L.T.at ALEX = U.T. +2Hours). In July (summer) 2002, the quietest month (mean of Am index 
$=18.03 \mathrm{nT}$, mean of Dst $=-5.53 \mathrm{nT}$, and mean of $\mathrm{vTEC}=45 \mathrm{TECU})$ during that year, there are many peaks of vTEC during the day especially after sunset.

In 2007 (part of the minimum of solar cycle 23), the maximum value of vTEC developed during May and minimum value during November /December, where many peaks of vTEC has be shown. During the deep solar minimum in 2007 several of the mean diurnal variations of vTEC showed two peaks in the morning and evening with a trough around midday. This is in agreement with the one observed at Ouagadougou during very quiet time (Ouattara and Amory- Mazaudier, 2012). Ouagadougou is an equatorial station, so it seems that during the deep solar minimum the equatorial anomaly is very spatially large and extends to tropical latitudes. This behavior is in the agreement with the explanation of Horvath and Essex (2000) which state that the common source of the night -time enhancement, develops at the magnetic equator latitude, is the westward electric field. Figure $4 \mathrm{a}, 4 \mathrm{~b}$, and $4 \mathrm{c}$ represented vTEC curves calculated for every day of the 11 years of our study period for the analysis of diurnal and seasonal solar variations for the three African stations. Also, they showed the two dimensional diurnal variation for three GPS stations ALEX, NKLG and RABT respectively; they explain how the behavior of vTEC hourly during 
the 11-years develops. Each figure is titled with the selected year, and has twelve months on its X-axis and 24 hours of vTEC on its Y-axis. Although sunset times for each station changes with each season, the local sunset time at ALEX is approximately at 19:00 L.T., at NKLG it is 19:30 L.T and 21:00 L.T at RABT.

From figure $4(\mathrm{a} \mathrm{b} \mathrm{c})$, it is evident that during the max of solar cycle in 2002 , the values of the vTEC during the winter months (Dec., Jan., Feb.) are greater than those in summer months (Jun., Jul., Aug.). This is winter anomaly, resulting from the closer distance from the sun to the earth and the direction of the wind from the summer season to the winter. The comparison between figure (4a-4b) shows that the winter anomaly is stronger during the years $(2001,2002,2003,2004,2011$ and, 2012) (corresponding to maximum, decrease and increasing phases of the solar cycle), and fade during the year (2005, 2006, 2007, 2008, 2009 and 2010). It seems to be undetectable in the deep min in year (2006 to 2009). Although, in figure 4c, the winter anomaly visible only in 2001-2002and 2011. This behavior might be attributed to the solar activity. When the solar activity is weaker, the winter anomaly is weaker. Rishbeth and Setty (1961) first suggested the possibility of composition change of the constituents being the cause of the winter 
anomaly. The anomaly might be due to a transequatorial neutral wind blowing from the summer hemisphere to the winter hemisphere.

Figure 4a (ALEX station) and 4c (RABT station) show that the nighttime vTEC enhancement arises during the equinox months of the intervals I,II,IV and it also appears in the winter months of the interval I,II . A glance on the figures $4 \mathrm{a}$ and $4 \mathrm{c}$ show that the vTEC determined from the stations ALEX and RABT are similar in the night time enhancement . This can be attributed the fact that they practically lie on the same latitude.

The vTEC determined from the stations NKLG (fig.4b), and RABT (fig.4c) are similar in winter anomaly. This is due to the fact that they practically lie on the same longitudinal zone. These results are in accordance with previously carried out measurements.

\subsection{Annual Variation}

This calculated only for ALEX. Figures 5a, 5b and 5c illustrate the annual variation of the mean monthly vTEC at ALEX at noon 10:00U.T. (ALEX . L.T. $=$ U.T. $+2 \mathrm{Hrs}$ ) during the sunspot solar cycle phases (I-II), III, and IV. See table (2).

Figure 5a shows the annual variation of vTEC in ALEX for the interval I and II from 2002-2005. The solid, dash, dash dot, and double dot lines 
represent the 2002, 2003, 2004, and 2005 respectively. The figure shows that the maximum values of peaks of ionization in March 2002 is approximately ( 99 TECU); however, the minimum values in October 2005 and about ( 23 TECU). In the decreasing phase of the solar cycle, the vTEC gradually decreases according to the amount of UV that reaches to Earth.

Figure $5 \mathrm{~b}$ shows the annual variation of vTEC at ALEX at interval III from 2006-2009. The solid, dash and dash dot lines represent the 2006, 2007, and 2009 respectively. The figure shows the maxim the greats of them appeared in April 2006 and the smallest is found during September 2007 the ratio between the value is about (April 2006/September 2007=26.98/15.69=1.7 TECU) appearing also on two minim the greats of them during the months August 2006 and the smallest is appeared during January 2009 and their ratio is about (August $2006 /$ January $2009=16.5 / 11.81=1.30$ TECU). Observed is also the transition from deep minim to the increasing phase solar cycle 24 . Also, figure 5c shows the annual variation of vTEC during the interval IV from 2010-2012. The solid, dash and dash dot lines represent the 2010, 2011, and 2012 respectively. The vTEC recorded the maximum values of peaks of ionization in October 2012 ( $~ 55$ TECU); however, the minimum values in March 2010 ( 27 TECU). The vTEC gradually 
increases according to the amount of UV that reaches to Earth in the increasing phase of the solar cycle.

In figure $5 \mathrm{a}, 5 \mathrm{~b}$ and $5 \mathrm{c}$, the maximum peak of ionization developed in equinox and the minimum value of it occurred in solstice. The greatest maximum of the VTEC appears in interval I and II during March/April while the smallest maximum appears in October/November. The minima of vTEC in the same intervals are found in January /February, July/August and December. For the interval III, the maxima are in April/May and October, April being the greatest of them. In the same interval, the minima are in January /February, August and December. For the interval IV, the greatest maximum appears in October and second in March/April. The two minima are in January, June-August.

From long term observations the maxima of vTEC in ALEX during intervals I, II are during March/April and October/November. During the deep minimum, it is observed that the maximum is shifted to April/May. In order to understand this behavior, we analyzed the average of the Dst index and Am index are calculated during the months of March during interval III (-10.69 nT and 9.83 nT) October (-7.99 nT and 10.68 nT), April (-11.8 nT and $13.408 \mathrm{nT})$, and September(-5.783 nT and $10.783 \mathrm{nT})$. It was found the Dst values of March and October are smaller than that values of 
April and September during interval III. Also, the Am value of the March is smaller than that value of April. Although, the Am values of September are approximately similar to the October.

We compare the Dst for intervals (I-II) and IV to explain the behavior of the data. The Dst index has values (-2 nT and $-6 \mathrm{nT})$ during January and July compared with those of Dec. and Aug. (-4 nT and -7 nT). Although, the Dst values of January and July has smaller magnitude disturbance than those values of December and August. The Am index shows reversed behavior. Am in January (8 nT) is greater than in December (6 nT) and Am in July $(13 n T)$ is greater than in August (9 nT).

The dipolar component of the solar magnetic field is observed to reverse polarity around the time of solar maximum, and reaches peak strength at the solar minimum. During the minimum of the solar cycle, the slow solar wind is twice as dense as and more variable in intensity than the fast solar wind; which originates from a region around the Sun's equatorial belt that is known as the "streamer belt" (K. May-Britt, 2004). Also, Co-rotating interaction region (CIR) are more common driven geomagnetic storms; which resulting during the minimum of the solar cycle from the interaction between the fast solar wind and slow solar wind (A. Balogh et al., 2000). Legrand and Simon 
(1989) showed that $91.5 \%$ of the geomagnetic activity is associated to the solar dipole (minimum of solar cycle) and only $8.5 \%$ of geomagnetic activity, essentially the shock activity related to CME to the sunspot solar cycle (maximum of solar cycle). The geomagnetic activity is one of the factors of the equinoctial asymmetry. Ouattara and Mazaudier (2012) showed the influence of the different type of magnetic activity on the behavior of the F2 layer at equatorial latitudes.

\subsection{Seasonal Variation}

Figure 6a shows seasonal variation of vTEC at local noon in ALEX station from 2002-2012 for all the phases (I, II, III, and IV) of the solar cycle. Black circles and gray squares represent the mean monthly values of ionization at vernal and autumnal equinox respectively.

Figure $6 \mathrm{~b}$ shows gray triangles-and black squares represent the mean monthly values of ionization at summer and winter solstice respectively.

In figure $6 \mathrm{a}$, the values of mean monthly TEC are greater in spring than in autumn except in 2009 and 2011. In Figure 6b, the mean monthly TEC in winter is greater than the summer ones, during the years 2002, 2003 and 
2004, i.e. during maximum and decreasing phases of solar cycle 23. The winter and summer TEC are equal during the years 2005, 2006, 2007 and 2008, during the deep solar minimum. From 2009 to 2012, i.e. during the increasing phase of solar cycle 24 , the mean monthly TEC in summer is greater than the winter ones, during the increase phase of solar cycle 24 .

The behavior of the curve $6 \mathrm{a}$ and $6 \mathrm{~b}$ correspond to the sunspot number variation presented in figure 7

During the maximum and decreasing phases of sunspot cycle (I and II), the vernal maximum is greater than the autumnal ones and ran vice-versa during the increasing phase (IV). The asymmetry between equinoxes and solstices which is observed in annual variation is due to geophysical parameters, magnetic indices (Triskova, 1989; Cliver et al, 2000; Cliver et al., 2001) and the $\mathrm{Bz}$ component of the interplanetary magnetic field (Russell and McPherron, 1973). The mechanisms invoked to explain such an asymmetry: 1) the axial hypothesis, 2) the Russell Mac Pherron (RM) effect and 3) the equinoctial hypothesis (Chaman Lal, 1996; Cliver et al., 2002).

Concerning the F2 layer and therefore the vTEC, the semiannual pattern with equinoctial and winter asymmetries can be explained in view of the following different mechanisms. The mechanisms are 1) the seasonal change of the 
ratio O/N2 (Rishbeth and Setty 1961, Rishbeth and Mueller Wodarg, 2006), 2) the Sun Earth distance; equinoctial hypothesis (Yonezawa, 1959; Rishbeth et al., 2000), and 3) waves and tides transmitted from the low thermosphere (Zou et al., 2000).

\subsection{Solar Cycle Variation}

Figure 7 shows the annual mean values of vTEC and Rz index behavior at local noon 10:00U.T. (U.T. +2Hrs = ALEX .L.T.) during the solar cycle phases variation from 2002-2012. Dash and solid line repented the Rz index and the vTEC, respectively.

Figure 8 shows the high positive correlation between Rz index (x-axis) and vTEC (y-axis) at 10:00 U.T. local noon for the selected time interval. Table 3 represents the seasonal variation of the correlation coefficient between $\mathrm{Rz}$ and vTEC. The correlation coefficient calculated for ALEX varies between (0.98-0.89) during vernal and autumnal equinox (0.98), during summer (0.94), and winter (0.89) solstices. The correlation coefficient during the selected years interval is about (0.98), as represented in figure 8 by solid line. The correlation is computed between the two series of the following data: 1) the arithmetic monthly mean of Rz index from 2002 to 2012, and 2) 
the arithmetic monthly mean of ALEX-TEC from 2002 to 2012, respectively.

The obtained correlation value are in accordance with those determined by Ouattara et al., (2009) in Africa and which lay between 0.948 and 0.977 for the solar cycles $20,21,22$. In contrary the three results are those obtain by Pham et al. (2011) in Asia which lay between 0.836 and 0.848 for the same solar cycles and unclear the same conditions.

\section{Conclusion}

In this paper we analyzed the time variations of the vertical TEC measured at the African site of Alexandria $\left(31.2167^{\circ} \mathrm{N} ; 29.9667^{\circ} \mathrm{E}\right.$, geographic) and compared the results with the vertical TEC observed at Rabat $\left(33.9981^{\circ} \mathrm{N}\right.$; $353.1457^{\circ} \mathrm{E}$, geographic) and Libreville $\left(0.3539^{\circ} \mathrm{N} ; 9.6721^{\circ} \mathrm{E}\right.$, geographic $)$. This period of investigation spanned through 2002-2012. The following conclusions can be drawn from the study:

1) The amplitude of the diurnal variation of vTEC depends on the solar cycle phase. This is well known and explained by the fact that the total 
ionization depends on the solar radiation related to the solar cycle phases.

2) During the deep solar minimum, in agreement with the observation at Ouagadougou, the shape of diurnal variation vTEC at ALEX station exhibits the same pattern of equatorial station in morning and evening peaks with trough around midday.

3) The diurnal variation of vTEC at Alex station exhibits a multi-peaks structure at solstices during quiet solar activity

4) The amplitude vTEC at NKLG is larger than the ones observed at ALEX and RABT. This is due to the fact that NKLG is located near the southern crest of the Equatorial Ionization anomaly.

5) The observations show the well-known winter anomaly. The summer ion loss is higher than the summertime production and as a consequence the vTEC is lower in local summer months. This phenomenon is mainly observed at mid-latitudes.

6) The seasonal variations of TEC allow identifying and characterizing solar cycle phase effects on vTEC in this area. In fact that

(i) During the deep solar minimum, vTEC presents equinox peaks in April /May and October. 
(ii) The winter anomaly, nighttime TEC enhancement and the presence of equinoctial peaks are most pronounced effects in vTEC during increasing and decreasing phase.

(iii) There is a strong asymmetry in the two equinoctial peaks (vernal > autumnal) and the location of the peaks occurred in March/April and October/November at the maximum of sunspot solar cycle and decreasing phase. This was attributed to $\mathrm{CME}$ and recurrent activities.

(iv) The asymmetry changes during the increasing phase of solar cycle 24 (autumnal > vernal).

All these news observations (i to iv) need to be explained; indeed it is the first time that the vTEC data are classified following the Legrand and Simon's classification (1989). More investigations with modeling are necessary. It is now necessary, to introduce in the model of the different sources of solar activity (CME, coronal hole CCIR etc...) in order to understand in more detail the TEC variability.

7) The highest positive correlation (0.98) between vTEC and Rz index occurred during vernal equinox. 
This detailed experimental analysis is the first step and more work is necessary for the modeling of the behavior of ionosphere at AlexandriaEgypt. It is also necessary to deploy more GPS in Africa in order to have a good resolution of vTEC all over this continent. 


\section{Acknowledgements}

Our sincere thanks go to all members of the Space Weather and Monitoring Center, SWMC, Helwan University for their ceaseless support. The $\mathrm{CFCCPhD}$ program is financially supported by the French-Egypt scientific year project that cooperate with the Department of Scientific and Technological Cooperation Embassy of France in the Arab Republic of Egypt French Institute of Egypt, LPP/Polytechnique/ UPMC/CNRS and Telecom Bretagne-Brest University. A GPS station were deployed in EGYPT under the ISWI (International Space Weather Initiative) project which follows the IHY (International Heliophysical Year) project. Our huge thanks go to the great efforts of the coordinators from all organizations (SWMC, Helwan University, CFCC, French-Egypt scientific year project, LPP/Polytechnique/UPMC/CNRS, Brest University, ISWI, and IHY). 


\section{References}

Abur-Robb, M. F. K., D.W. Windle, 1969. On the day and night reversal in Nm F2 North-South asymmetry, Planet. Space Sci., 17, 97-106.

Arendt, P. R., and H. Soicher, 1964. Downward electron flux at $1000 \mathrm{~km}$ altitude from electron content measurement at mid-latitudes, Nature, 204, $983 \pm 984$

Adohi, J-P., P.M. Vila, C. Amory-Mazaudier, M. Petitdidier, 2008. Equinox transition at the magnetic equator in Africa: Analysis of ESF ionograms, Ann. Geophys., 26, 7, 1777-1792.

Anderson, D. N., 1981. Modeling the ambient, low latitude $F$ region ionosphere-A review, J. Atmos. Terr. Phys., 43, 753- 762.

Anderson, D. N., 1973a. A theoretical study of the ionospheric $F$ region equatorial anomaly, I Theory, Planet. Space Sci., 21, 409-419. 
Anderson, D. N., 1973b. A theoretical study of the ionospheric $F$ region equatorial anomaly, II Results in the American and Asian sectors, Planet. Space Sci., 21, 421-442.

Bailey, G. J., R. Sellek, and N. Balan (1991), The effect of interhemispheric coupling on nighttime enhancements in ionospheric total electron content during winter at solar minimum, Ann. Geophys., 9, 738-747.

Balan, N., and P. B. Rao, 1987. Latitudinal variations of nighttime enhancements in total electron content, J. Geophys. Res., 92, 3436 \pm 3440 .

Balan, N., Bailey, G. J., and Balachandran Nair, R, 1991. Solar and magnetic activity effects on the latitudinal variations of nighttime TEC enhancement, Ann. Geophysicae, 9, 60-69.

Balan, N., J.J. Bailey, R.J. Moffett, Y.Z. Su, J.E. Titheridge, 1995. Modeling studies of the conjugate-hemisphere differences in ionospheric ionization at equatorial anomaly latitudes, J. Atmos. Terr. Phys. 57(3), 279-292. 
Balogh. A, J. T. Gosling, J. R. Jokipii, R. Kallenbach, H. Kunow Corotating Interaction Regions, Corotating Interaction Regions Proceedings of an ISSI Workshop, 6-13 June 1998, Bern, Switzerland, Springer (2000), Hardcover, ISBN 978-0-7923-6080-3, Softcover, ISBN 978-90-481-5367-1

Bertin, F., and J. P. Lepine (1970), Latitudinal variation of total electron content in the winter at middle latitudes, Radio Sci., 5(6), 899-906, doi:10.1029/RS005i006p00899.

Chaman Lal, 1996. Seasonal trend of geomagnetic activity derived from solar-terrestrial geometry confirms an axial-equinoctial theory and reveals deficiency in planetary indices, J. Atmos. Terr. Phys., 58, 13, 1497-1506.

Cliver E. W, Y. Kamide, A.G. Ling, 2002. The semiannual variation of geomagnetic activity: phase and profiles for 130 years of aa data, $J$. Atmos. Terr. Phys., 64, 47-53.

Cliver E. W., Y. Kamide, A.G. Ling, 2000. Mountain versus valleys: Semiannual variation of geomagnetic activity, J. Geophys. Res., 105, 
A2, 2413-2424.

Cliver E. W., Y. Kamide, A.G. Ling, N. Yokoyama, 2001. Semiannual variation of the geomagnetic Dst index: Evidence for a dominant non storm component, J. Geophys. Res., 106, A10, 21,297-304.

Crain, D.J., R.A. Heelis, G.J. Bailey, 1993. Effects of electrical coupling on equatorial ionospheric plasma motions-When is the $\mathrm{F}$ region a dominant driver in the low latitude dynamo? J. Geophys. Res., 98, 6033.

Davies, K., A.K. Anderson, P.W. Degenhart, G.K. Hartmann, R. Leitinger, 1979. Night-time increases in total electron content observed with ATS 6 radio beacon, J. Geophys. Res., 84, 1536-1542.

Da Rosa, A. V., and F. L. Smith III (1967), Behavior of the nighttime ionosphere, J. Geophys. Res., 72(7), 1829-1836, doi:10.1029/JZ072i007p01829.

Evans, J. V. (1965a), An F region eclipse, J. Geophys. Res., 70(1), 131-142, doi:10.1029/JZ070i001p00131. 
Evans, J. V. (1965b), On the behavior of foF 2 during solar eclipses, J. Geophys. Res., 70(3), 733-738, doi:10.1029/JZ070i003p00733.

Evans, J. V. (1965c), Cause of the midlatitude evening increase in foF2, J. Geophys. Res., 70(5), 1175-1185, doi:10.1029/JZ070i005p01175.

Evans, J. V. (1965d), Cause of the midlatitude winter night increase in foF2, J. Geophys. Res., 70(17), 4331-4345, doi:10.1029/JZ070i017p04331.

Farley, D. T., E. Bonelli, B.G. Fejer, and M.F. Larsen, 1986. The prereversal enhancement of the zonal electric field in the equatorial ionosphere. $J$. Geophys. Res., 91, 13723.

Garner, T. W., P. G. Richards, and R. H. Comfort (1994), Anomalous nighttime electron temperature events over Millstone Hill, J. Geophys. Res., 99(A6), 11,411-11,415, doi:10.1029/94JA00261.

Hanson, W. B., B. J . Moffett, 1966. Ionization transport effects in the equatorial F region, J. Geophys. Res., 71, 5559-5571. 
Heelis, R. A., P.C. Kendall, R.J. Moffett, D.W. Windle, H. Rishbeth, 1974. Electrical coupling of the E- and F-regions and its effect on F-region drifts and winds, Planet. Space Sci., 22, 743.

Horvath, I., E.A. Essex, 2000. Using observations from the GPS and TOPEX satellites to investigate night-time TEC enhancements at midlatitudes in the southern hemisphere during a low sunspot number period. $J$. Atmos. Terr. Phys., 62, 371-391

Jain, A. R., and P. J. S. Williams (1984), The maintenance of the night-time ionosphere at mid-latitudes. II. The ionosphere above St. Santin, J. Atmos. Terr. Phys., 46, 83-89.

Jakowski, N., A. Jungstand, L. Lois, and B. Lazo (1991), Night-time enhancements of the F2-layer ionization over Havana, Cuba, J. Atmos. Solar Terr. Phys., 53, 1131-1138.

Jakowski, N., and M. Förster (1995), About the nature of the night-time winter anomaly effect (NWA) in the F-region of the ionosphere, Planet. Space Sci., 43, 603-612. 
Klobuchar, J. A., 1996. Ionospheric effects on GPS, in: Global Positioning System: Theory and application Vol. 1, edited by: Parkinson, B. W. and Spilker, J. J., American Institute of Aeronautics and Astronautics INC.

Klobuchar, J.A., J. Aarons, H. Hajeb Hosseinieh, 1968. Mid-latitude nighttime total electron content behavior during magnetically disturbed periods, $J$. Geophys. Res., 73, 7530-7534.

Komjathy A., B.D. Wilson, T.F. Runge, B.M.Boulat, A.J. Mannucci, L. Sparks, M.J. Reyes, 2002. A new ionospheric model for wide area differential GPS: the multiple shell approach, IONNTM2002.

Legrand and Simon , 1989. Solar cycle and geomagnetic activity: a review for geophysicists. Part I. The contributions to geomagnetic activity of shock waves and of the solar wind. Annales Geophysicae 7(6), 565-578.

Leintinger, R., G. K. Hartman, W. Degenhart, A. Hedberg, P. Tanskanen, 1982. The electron content of the ionosphere and the southern boundary of diffuse aurora, J. Atmos. Terr. Phys., 44, 369-374. 
May-Britt K. (2004) Space Physics: An Introduction to Plasmas and Particles in the Heliosphere and Magnetospheres Springer. ISBN 3-54020617-5.

Meggs, R.W., C. N. Mitchell, 2006. A study into the errors in vertical total electron content mapping using GPS data, Radio Science, v41, RS1008.

Mikhailov, A. V., T. Y. Leschinskaya, and M. Förster (2000), Morphology of NmF2 nighttime increases in the Eurasian sector, Ann. Geophys., 18, $618-628$.

Moeketsi, D.M., W.L. Combrinck, L.A. McKinnell, M. Fedrizzi, 2007. Mapping GPS-derived ionospheric Total Electron Content over Southern Africa during different epochs of solar cycle 23, Adv. Space Res., 39, 5, 821829.

Norsuzila Y., M. Abdullah, M. Ismail, A. Zaharim, 2009. Model Validation for Total Electron Content (TEC) at an Equatorial Region, European Journal of Scientific Research, 28, 4, 642-648. 
Obrou,,O.K., M.N. Mene, A.T. Kobea, K.Z. Zaka, 2009. Equatorial Total Electron Content (TEC) at low and high solar activity, Adv. Space Res., 43, $11,1757-1761$.

Olapido, O.A., J.O. Adeniyi, S.M. Radicella, O.K. Obrou, 2008. Variability of equatorial ionospheric density at fixed heights below the F2 peak, $J$. Atmos. Terr. Phys., 70, 1056-1065.

Ouattara, F., C. Amory-Mazaudier, R. Fleury, P. Lassudrie-Duchesne, P. Vila, M. Petididier, 2009. West African equatorial ionospheric parameters climatology based on Ouagadougou ionosonde station data from June 1966 to February 1998, Ann. Geophys., 27, 2503-2514.

Ouattara F., C. Amory-Mazaudier, 2012. Statistical study of the Equatorial F2 layer at Ouagadougou during solar cycles 20, 21, 22 using Legrand's and Simon's classification of geomagnetic activity, Space Weather and Space Climate .

Ouattara F., 2012. foF2 Long Term trends at Ougadougou station, British Journal of Applied Science and Technlology, 2(3), 240-253. 
Ouattara, F., A. Gnabahou, C. Amory-Mazaudier, 2012. Seasonal, diurnal and solar-cycle variations of electron density at two West Africa equatorial ionization anomaly stations, International Journal of Geophysics., ID 640463.

Ouattara.F., C. Mazaudier, 2012. Statistical study of the equatorial F2 layer critical frequency at Ouagadougou during solar cycles 20, 21 and 22, using Legrand and Simon's classification of geomagnetic activity, J. Space Weather Space Clim., 2.

Pham Thi Thu, H., C. Amory-Mazaudier, M. Le Huy, Time variations of the Ionosphere at the northern tropical crest of ionization at Phu ThuyVietnam, Ann. Geophys. 29, 197-207.

Richards, P. G., et al. (2000), On the relative importance of convection and temperature to the behavior of the ionosphere in North America during January 6-12, 1997, J. Geophys. Res., 105(A6), 12,763-12,776, doi:10.1029/1999JA000253. 
Rishbeth, H., C.S.G.K. Setty, 1961. The layer at sunrise, J. Atmos. Terr. Phys., 20, 263-276.

Rishbeth, H., 1971. Polarization electric fields produced by winds in the equatorial F region, Planet. Space Sci., 19, 357.

Rishbeth, H., 1972. Thermospheric winds and the F-region: a review, J. Atmos. Terr. Phys., 34, 1-47

Rishbeth. H., 1974. Some problems of the F region, Radio Science, Volume 9, Issue 2, pages 183-187.

Rishbeth, H., I.C.F. Muller-Wodarg, L. Zou, T.J. Fuller-Rowell, G.H. Millward, R.J. Moffett, D.W. Idenden, A.D. Aylward, 2000a. Annual and semiannual variation in the ionospheric F2-layer: II. Physical discussion, Ann. Geophys., 18, 945-956.

Rishbeth, H., I.C.F. Mueller-Wodarg, 2006.Why is there more ionosphere in January than in July? The annual asymmetry in the F2-layer, Ann. Geophys., 24, 3293-3311. 
Roble, R.G., Salah. J. E. and B. A. Emery, 1977.The Seasonal Variation of the diurnal thermospheric winds over Millstone Hill during solar cycle maximum, JATP, 39, 503.

Russell , C.T., R.C. Mc Pherron, 1973. Semi annual of Geomagnetic activity, J. Geophys. Res., 78, 92-99.

Sardon E., A. Rius, N. Zarraoa, 1994. Estimation of the Transmitter and Receiver Differential Biases and the Ionospheric Total Electron Content from Global Positioning System Observations, Radio Sci., 29, 577-586.

Smith D., A.E. Araujo-Pradere, C. Minter, T. Fuller-Rowell, 2008. A comprehensive evaluation of the errors inherent in the use of a twodimensional shell for modelling the ionosphere, Radio Sci., 43, RS6008 .

Sojka, J. J., R.W. Schunk, 1985. A Theoretical Study of the Global F region for June Solstice, Solar Maximum, and Low Magnetic Activity, J. Geophys. Res., 90(A6), 5285-5298. 
Sojka, J. J., R.W. Schunk, 1989. Theoretical Study of the Seasonal Behavior of the Global Ionosphere at Solar Maximum, J. Geophys. Res., 94(A6), 6739-6749.

Sterling, D. L., W.B. Hanson, R.J. Moffett, R.G.Baxter, 1969. Influence of electromagnetic drifts and neutral air winds on some features of the F2 region, Radio Sci., 4, 1005-1023.

Thiam, N., F. Ouattara, G. Allain, C. Amory Mazaudier, R. Fleury, P. Lassudrie Duchesne, 2012. Variation of F2 layer critical frequency with solar cycle at Dakar station, J. Sci. (in French), 11, 2, 16-20.

Titheridge, J. E., 1972. The total electron content of the southern midlatitude ionosphere, 1965-1971, J. Atmos. Terr. Phys., 35, 981-1001.

Triskova, L.,1989. The vernal-autumnal asymmetry in the seasonal variation of geomagnetic activity, J. Atm. Terrestr. Phys.,51, 111-118.

Tsai, H.F., J.Y. Liu, W.H. Tsai, C.H. Liu, 2001. Seasonal variations of the 
ionospheric total electron content in Asian equatorial anomaly regions, $J$. Geophys. Res., 106, A12, 30363-30369.

Yonezawa, T., 1959. On the seasonal and non-seasonal annual variations and the semiannual variation in the noon and midnight densities of the F2 layer in middle latitudes II, J. Radio Res. Labs. Japan, 6, 651-668.

Zou, L., H. Rishbeth, I.C.F. Muller-Wodarg, A.D. Aylward, G.H. Millward, D.W. Idenden, R.J. Moffett, 2000. Annual and semiannual variation in the ionospheric F2-layer. I. Modelling, Ann. Geophys., 18, 945-956. 
Page | 42 


\section{Table Captions}

Table 1: Geographic and geomagnetic coordinates of GPS stations .

Table 2: Classification of selected years and sunspot numbers according to the solar cycle phases.

Table 3: Correlation coeffcient between vTEC at ALEX and Rz index during 2002- 2012 according to the seasonal variation . 


\section{Figures Captions}

Figure 1 Map of the GPS stations

Figure 2 Variation of vTEC according to UT time for a)AIEX and b)NKLG stations. The red dots are based on our method on Rinex measures of 7 April 2012; the resulting continuous line (in blue) represents the diurnal variation at the vertical of each station.

Figure 3 Comparison between the diurnal variation of mean monthly vTEC at ALEX at maximum (2002) and at minimum (2007) of the solar cycle 23.

Figure 4a Two dimensional (2D) Diurnal variation of hourly vTEC at ALEX from 2002-2012.

Figure 4b Two dimensional (2D) Diurnal variation of hourly vTEC at NKLG from 2002-2012.

Figure 4c Two dimensional (2D) Diurnal variation of hourly vTEC at RABT from 2002-2012.

Figure 5 Annual variations of mean monthly values of vTEC at ALEX a)during the solar cycle phases (I, II) from 2002-2005 b) during the solar cycle phase (III) from 2006-2009 c) during the solar cycle phase (IV) from 2010-2012.

Figure 6 Seasonal variation of vTEC at ALEX from 2001-2012 during the solar cycle phases (I, II, III, IV) a)during vernal and autum b) during winter and summmer.

Figure 7 Solar cycle variation of vTEC at ALEX and Rz from 2002 to 2013

Figure 8 Correlation variation between vTEC at ALEX and Rz from 2002 to 2013 
Table 1

\begin{tabular}{|c|c|c|c|c|c|c|c|}
\hline \multirow{2}{*}{ Id } & \multirow{2}{*}{ City } & \multirow{2}{*}{ Location } & \multicolumn{2}{|c|}{ Geographic } & \multicolumn{2}{|c|}{ Geomagnetic } & \multirow{2}{*}{$\mathrm{D}(\mathrm{deg})$} \\
\hline & & & Longitude & Latitude & Longitude & Latitude & \\
\hline ALEX & Alexandria & Egypt & $29.9110 \mathrm{E}$ & $31.1971 \mathrm{~N}$ & $107.80 \mathrm{E}$ & $28.47 \mathrm{~N}$ & 3.991 \\
\hline RABT & Rabat & Morocco & $7.1457 \mathrm{~W}$ & $33.9981 \mathrm{~N}$ & $72.18 \mathrm{E}$ & $37.37 \mathrm{~N}$ & -2.236 \\
\hline NKLG & Libreville & Gabon & $9.6721 \mathrm{E}$ & $0.3539 \mathrm{~N}$ & $82.30 \mathrm{E}$ & $1.68 \mathrm{~N}$ & -2.452 \\
\hline
\end{tabular}

(D is the Magnetic Declination)

Table 2

\begin{tabular}{||l|l|l|l||}
\hline \hline Interval & Years & Sunspots index & Solar Cycle Phases \\
\hline I & 2002 & $80 \leq R_{z} \leq 116$ & The max of solar cycle 23 \\
\hline II & $\begin{array}{l}2003- \\
2005\end{array}$ & $20 \leq R_{z} \leq 80$ & Decreasing phase of solar cycle 23 \\
\hline III & $\begin{array}{l}2006- \\
2009\end{array}$ & $0 \leq R_{z} \leq 20$ & Deep solar minimum \\
\hline IV & $\begin{array}{l}2010- \\
2012\end{array}$ & $20 \leq R_{z} \leq 80$ & Increasing phase of solar cycle 24 \\
\hline
\end{tabular}

Table 3

\begin{tabular}{||l|l|l|l|l||}
\hline \hline \multicolumn{3}{||l||}{ Correlation Coefficient of vTEC at ALEX with Rz index at } \\
\hline $\begin{array}{l}\text { Vernal } \\
\text { Equinox }\end{array}$ & $\begin{array}{l}\text { Summer } \\
\text { Solstice }\end{array}$ & $\begin{array}{l}\text { Autumn } \\
\text { Equinox }\end{array}$ & $\begin{array}{l}\text { Winter } \\
\text { Solstice }\end{array}$ & $\begin{array}{l}\text { Total interval } \\
2002-2012\end{array}$ \\
\hline 0.98 & 0.94 & 0.95 & 0.89 & 0.90 \\
\hline
\end{tabular}




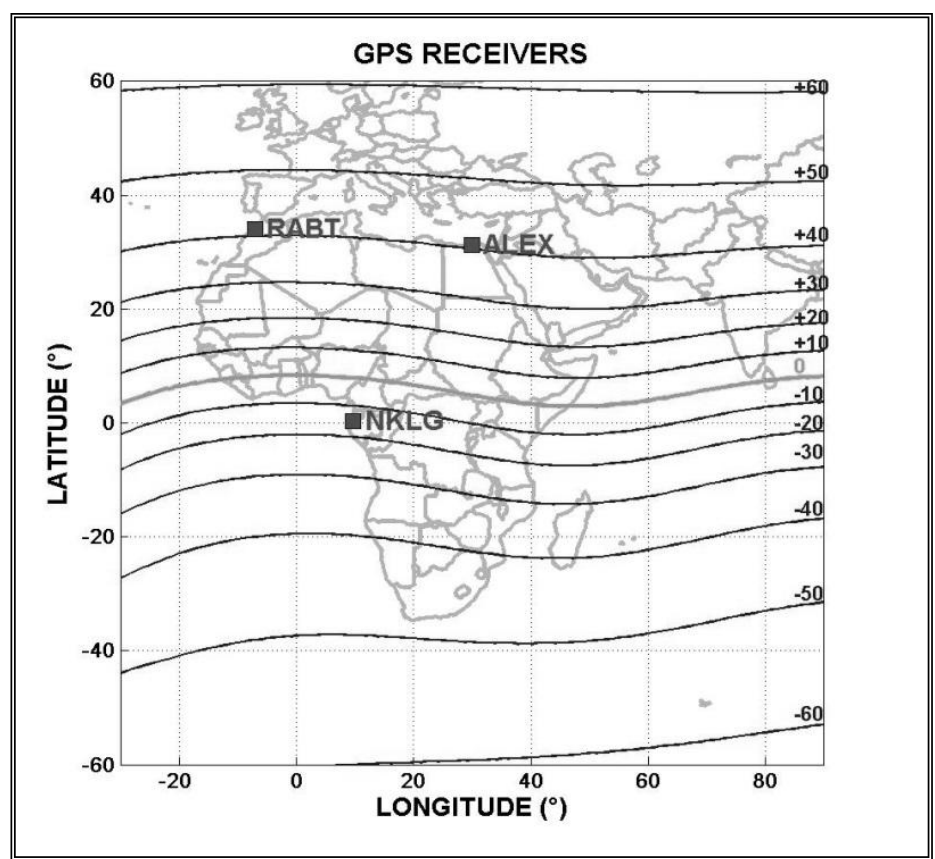

Figure 1 

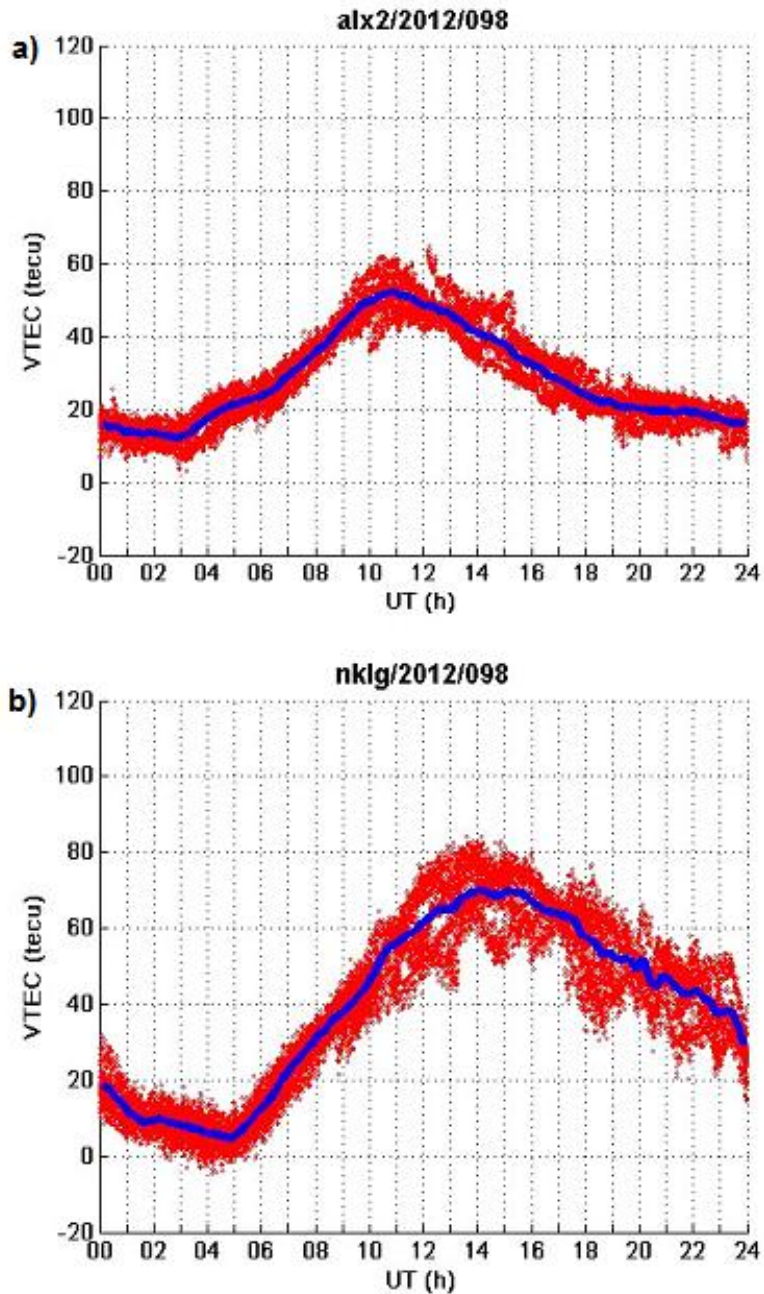

Figure 2 


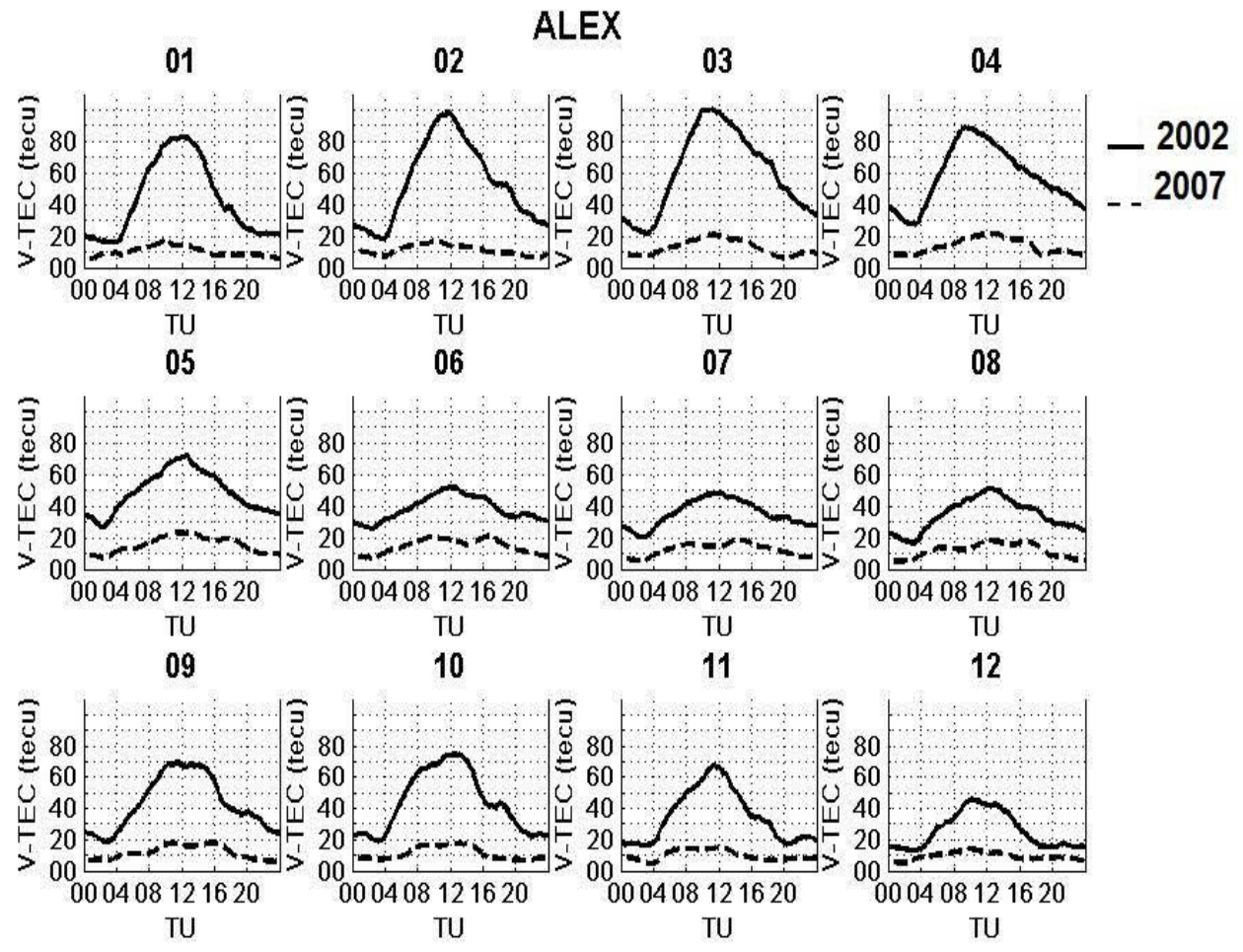

Figure 3 

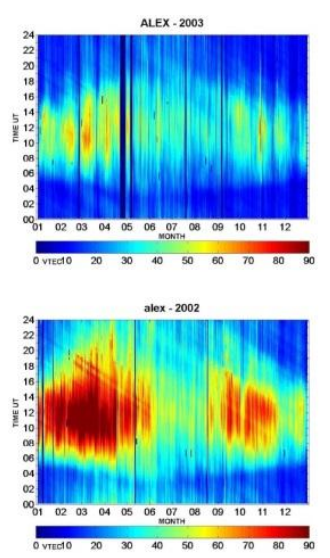

Figure 4a
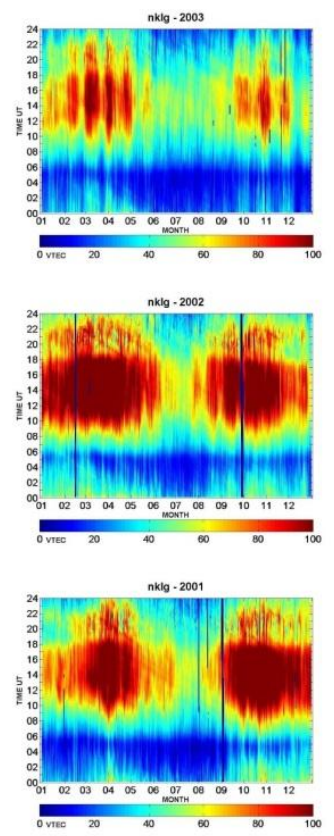

Figure 4b
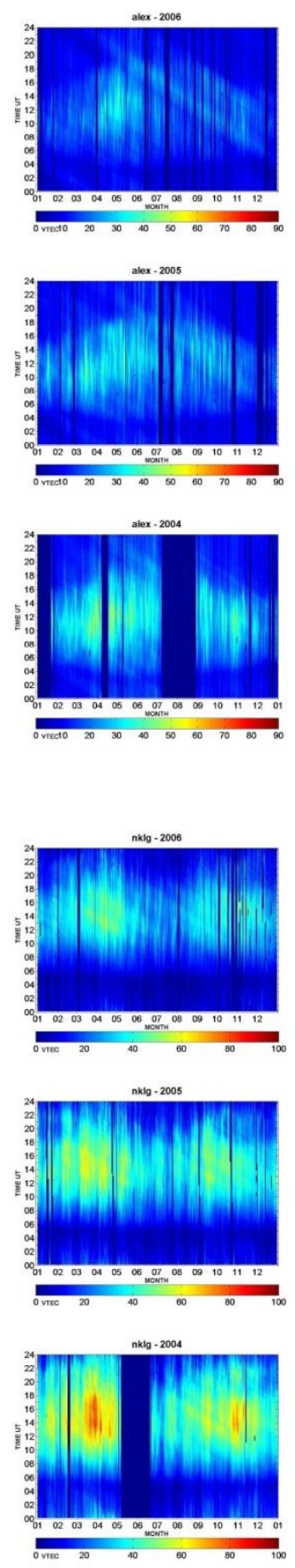

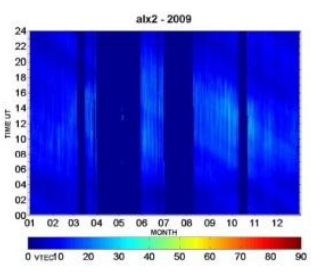

ALX2-2008
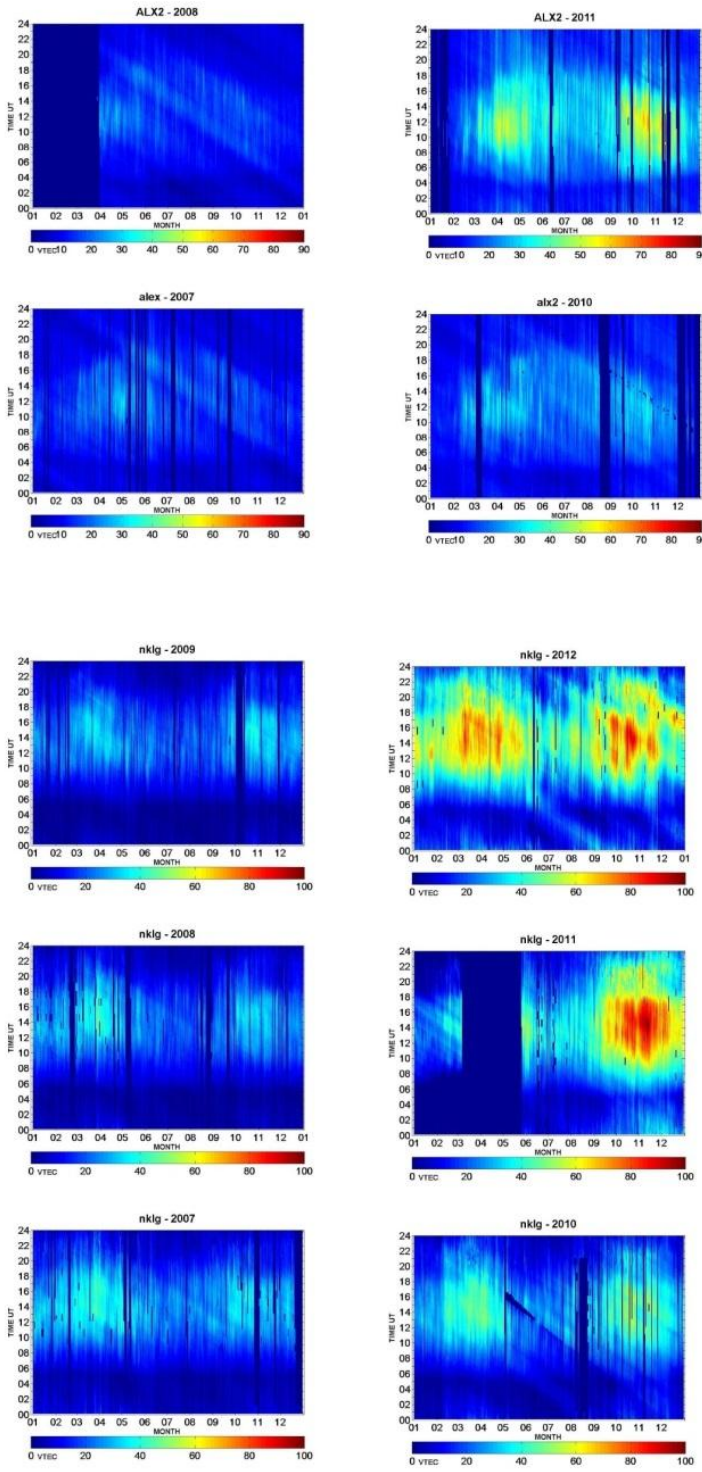

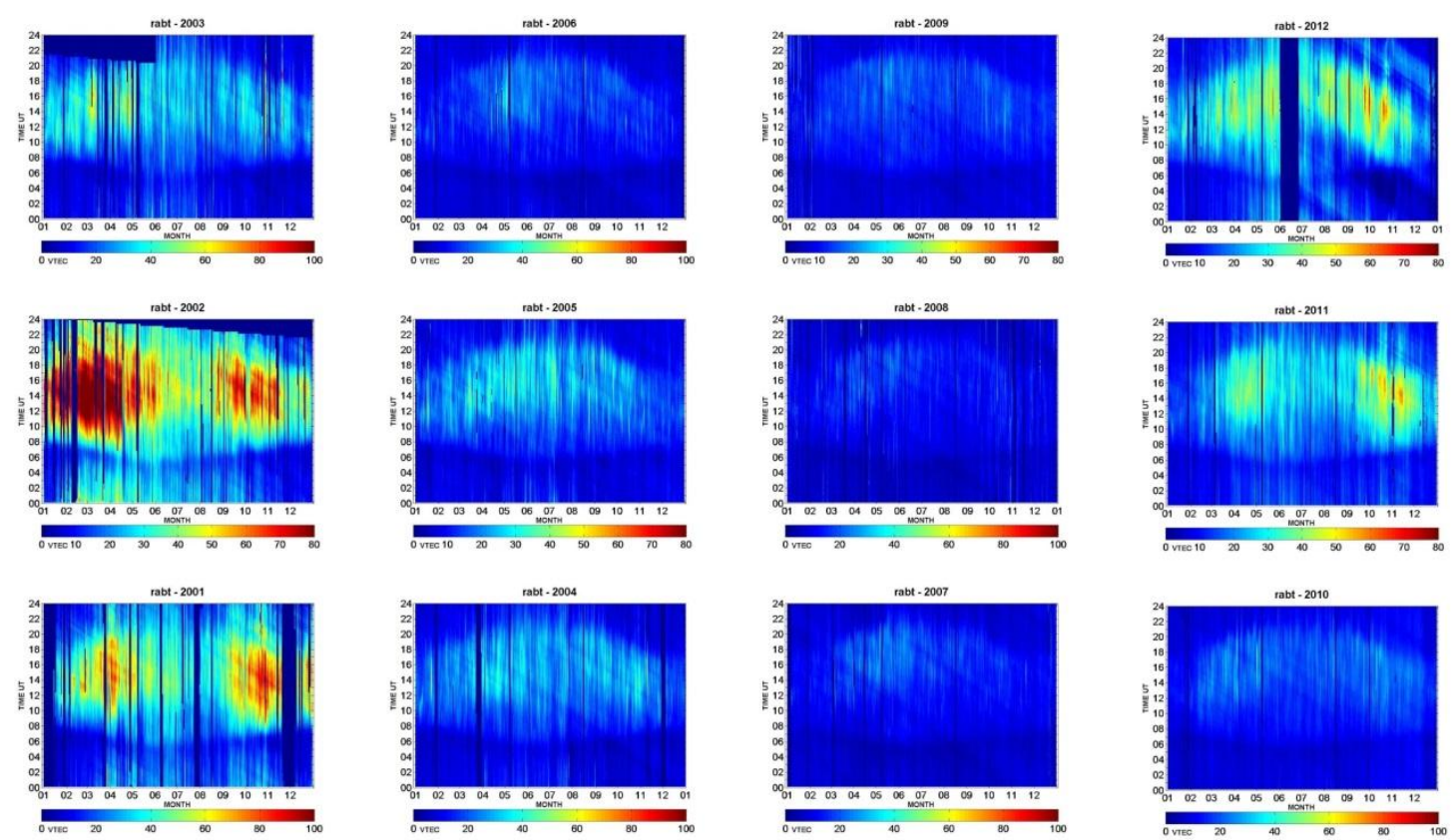

Figure 4c

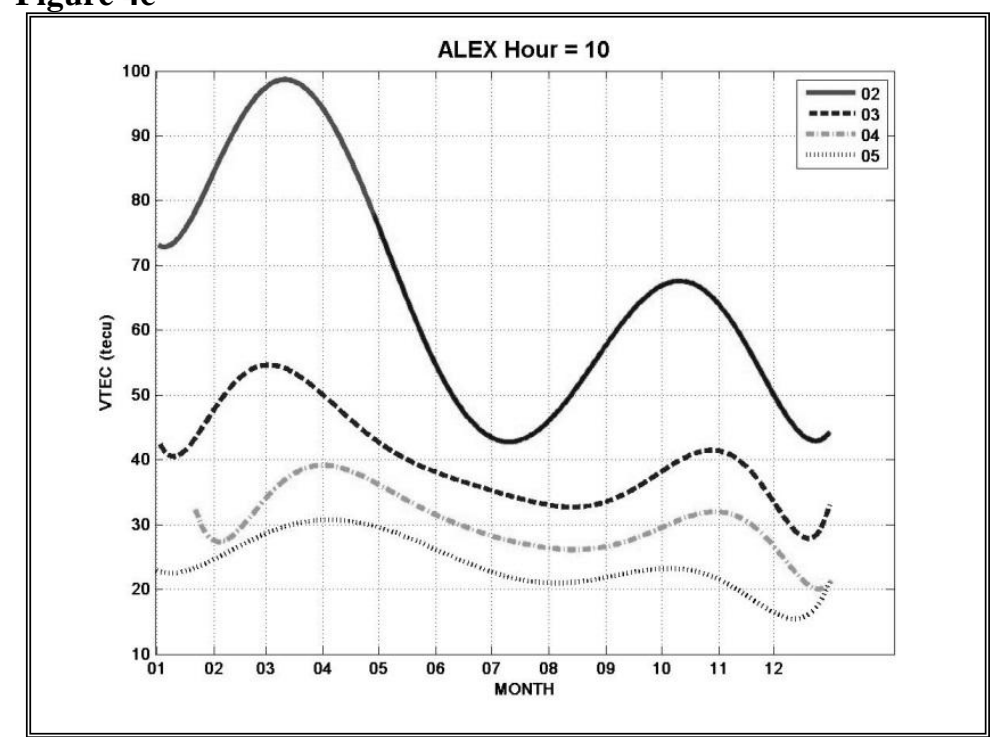

Figure 5a 


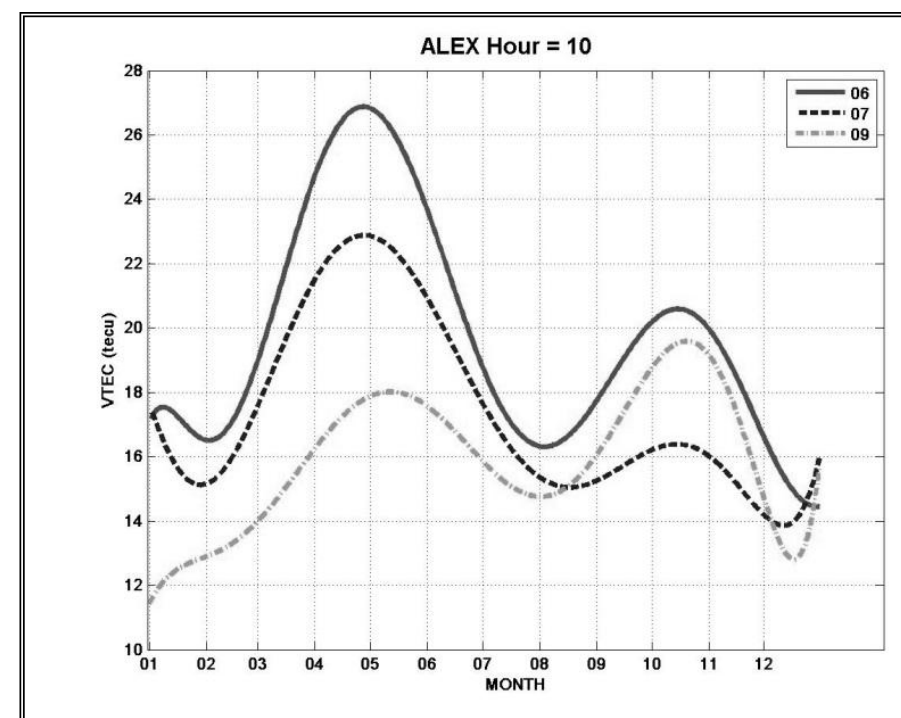

Figure Sb

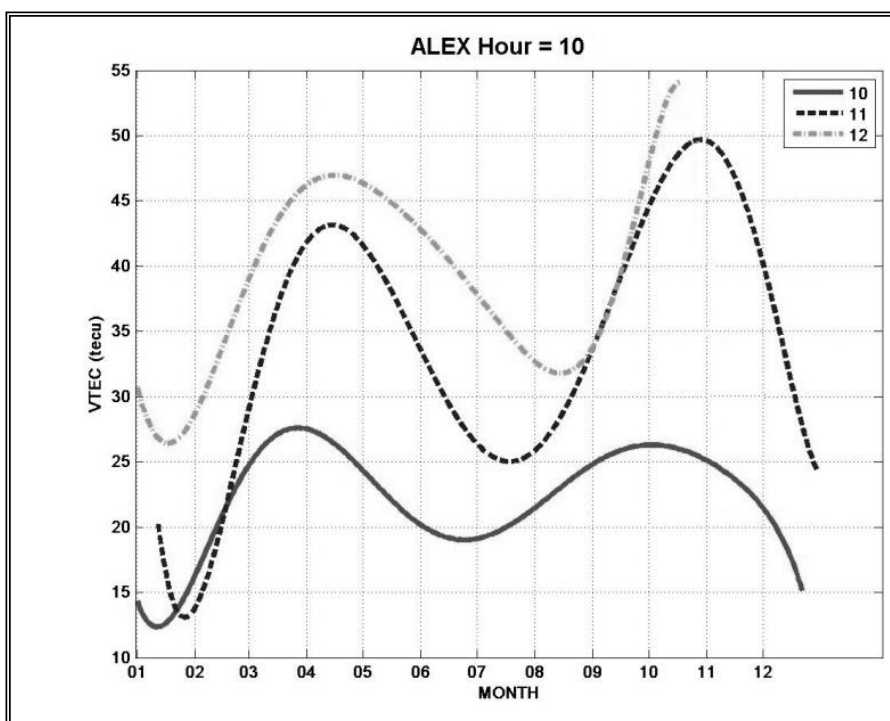

Figure sc

Page | 51 


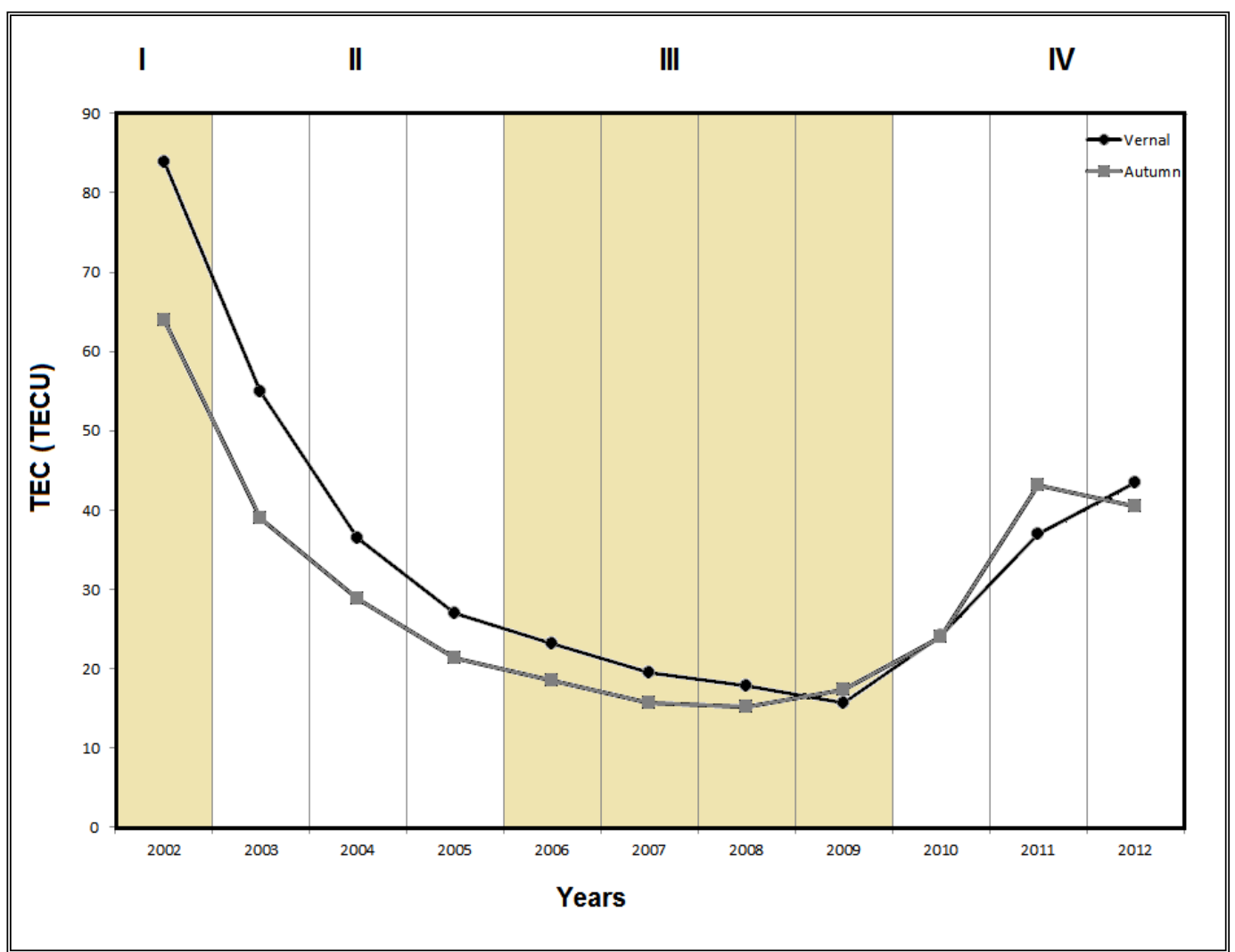

Figure 6a

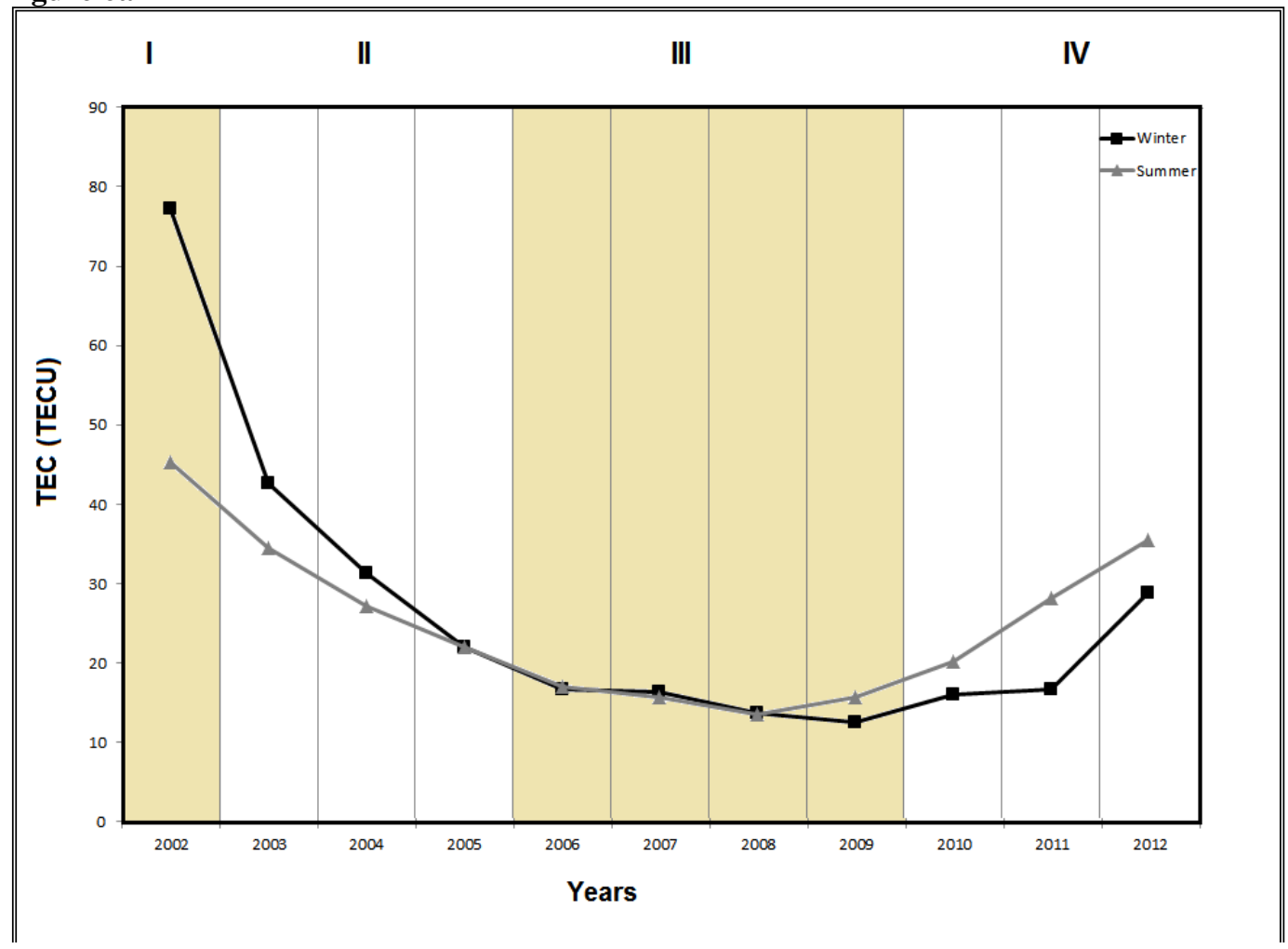

Figure 6b

Page $\mid 52$ 


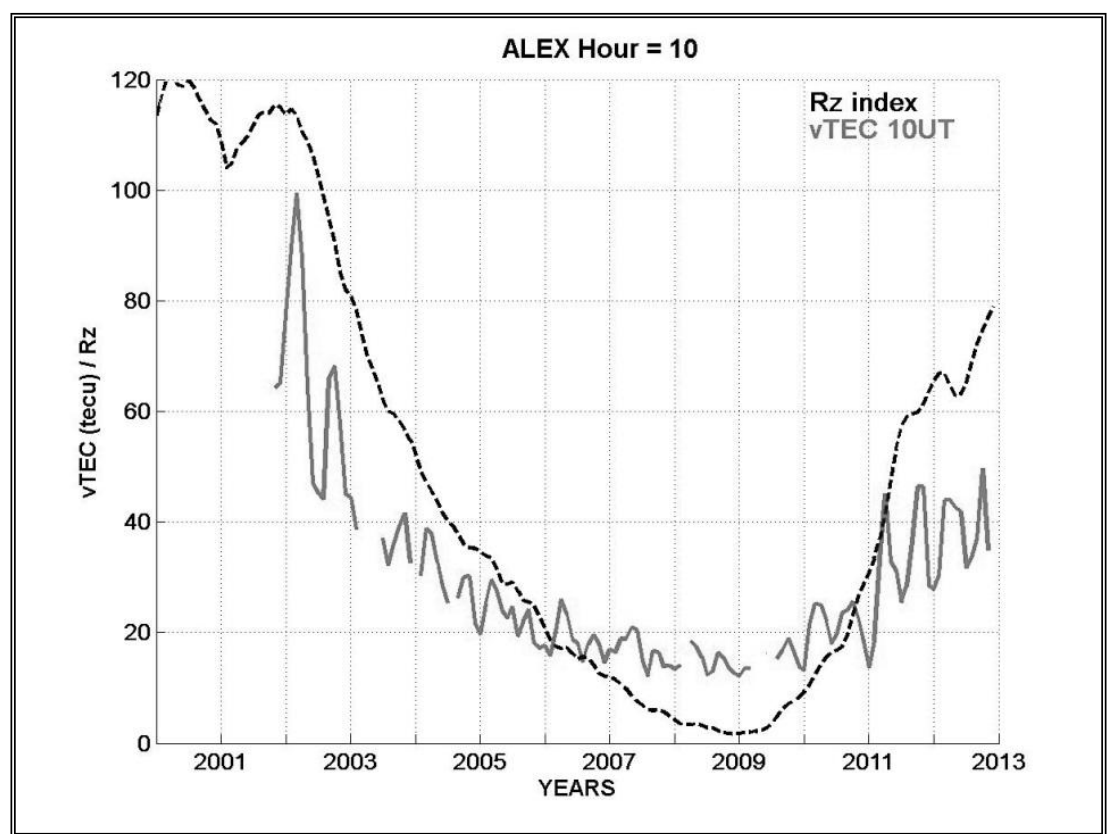

Figure 7

Page $\mid 53$ 


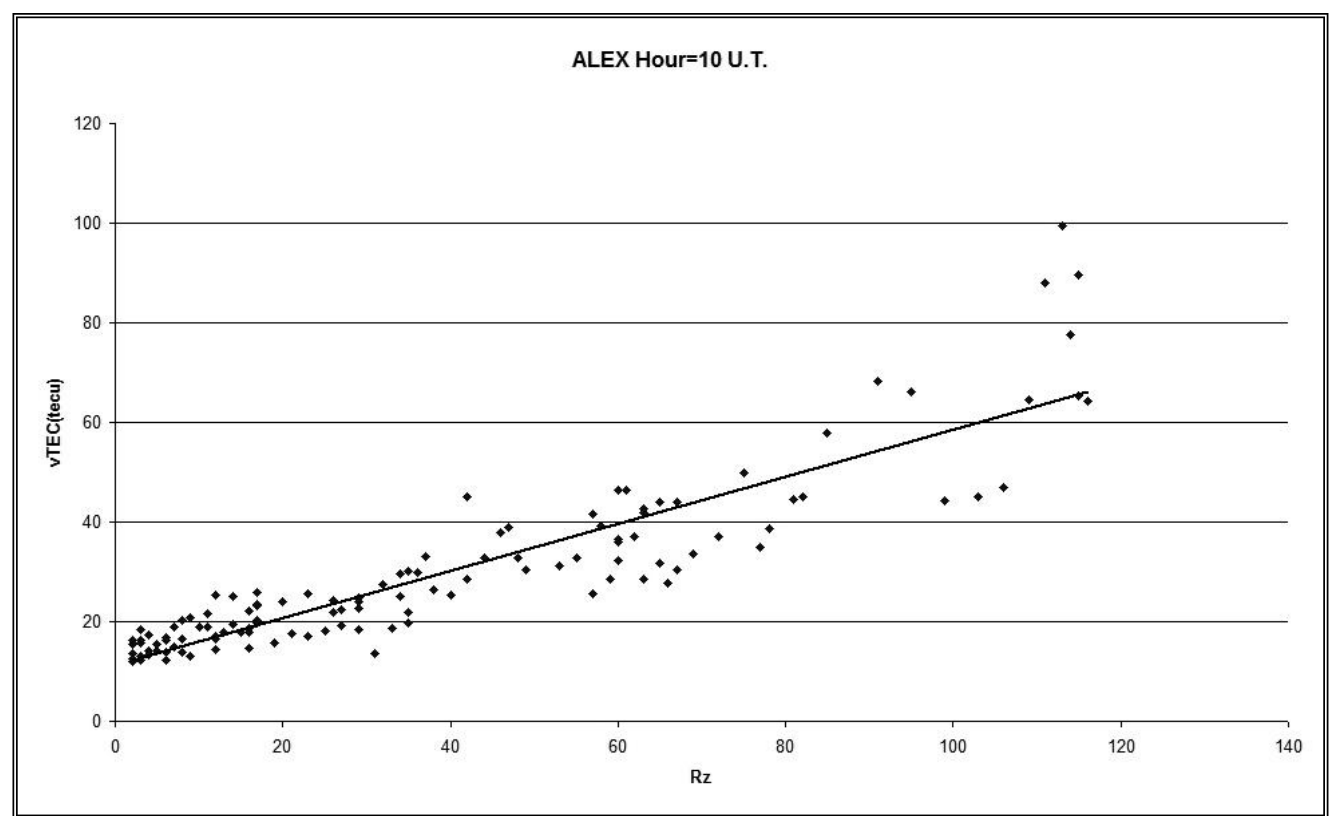

Figure 8 